\title{
Nucleotide Sequence and Complementation Analysis of a Polycistronic Sporulation Operon, spoVA, in Bacillus subtilis
}

\author{
By P. FORT $\dagger$ AND J. ERRINGTON* \\ Microbiology Unit, Department of Biochemistry, University of Oxford, Oxford OXI 3QU,UK
}

(Received 16 August 1984 ; revised 14 November 1984)

\begin{abstract}
We have determined the nucleotide sequence of a $3706 \mathrm{bp}$ stretch of Bacillus subtilis chromosomal DNA that complements all known spoVA mutations. The sequence contains five consecutive large open reading frames capable of encoding proteins of molecular weights ranging from approximately 15000 to 36000 . Analysis using integrational plasmids suggests that the region is likely to be transcribed as a single mRNA. A novel form of complementation analysis, based on derivatives of bacteriophage $\phi 105$ carrying the cloned spoVA locus, has been used to define four distinct complementation groups among the eight previously characterized spoVA mutations. The spoVA locus is the largest polycistronic sporulation operon yet characterized.
\end{abstract}

\section{INTRODUCTION}

More than 50 chromosomal loci necessary for normal sporulation and/or germination have been identified by mutagenesis and genetic mapping of the Bacillus subtilis chromosome (Piggot \& Coote, 1976; Piggot et al., 1981). However, the numbers of genes per locus, and the mechanisms controlling the sequential expression of these genes, have not been elucidated. Several sporulation and germination genes have recently been cloned by a variety of methods (see, for example, Segall \& Losick, 1977; Kawamura et al., 1979; Liu et al., 1982; Jenkinson \& Mandelstam, 1983; Savva \& Mandelstam, 1984; Errington, 1984). However, in most cases it has not been possible to determine whether or not the complete locus was cloned, since each was defined by relatively few spo mutations. The nucleotide sequences have been determined for three of these cloned loci : spoOF (Shimotsu et al., 1983), spoOH (Ramakrishna et al., 1984) and spoIIA (Fort \& Piggot, 1984). Of these loci, only spoIIA was shown to contain more than one gene. Three open reading frames (ORFs), preceded by ribosome binding sites (Shine \& Dalgarno, 1974). were identified; they are probably transcribed as a single messenger RNA (Piggot et al., 1984).

A $7 \mathrm{kbp}$ fragment of B. subtilis chromosomal DNA, cloned in bacteriophage $\phi 105$, was shown to contain both the spoIIA locus and a second locus, spoVA (Savva \& Mandelstam, 1984). The map positions and associated phenotypes of eight mutations in the spoVA locus have been determined (Errington \& Mandelstam, 1983, 1984). Although the spoIIA and spoVA loci may be contiguous, they are probably transcribed separately (Piggot $e t$ al., 1984). The total map distance between mutations at the extremities of the spoVA locus (recombination index, RI, approximately 0.3 ) was greater than that between the extreme spoIIA mutations (RI approximately $0 \cdot 2$ ) (Errington \& Mandelstam, 1984). Thus, it seemed likely that the spoVA locus also contained more than one gene.

\footnotetext{
† Permanent address: Laboratoire de Biologie Moléculaire, Université de Sciences et Techniques du Languedoc, Place E. Bataillou, 34060 Montpellier Cedex, France.
}

Abbretiation: ORF, open reading frame. 
We have now used physical and genetic methods to determine the number of genes in the spoV $A$ locus, and their organization. We have determined the nucleotide sequence of a $3706 \mathrm{bp}$ long segment of DNA that contains the complete spoVA locus. It includes five consecutive ORFs, and we have obtained evidence that the locus is probably transcribed as a single mRNA. Complementation analysis of the eight previously characterized spoVA mutations indicates that these lie in at least four different genes, and these genes are tentatively assigned to ORFs in the nucleotide sequence.

\section{METHODS}

Bacterial strains, plasmids and phages. These are listed in Table 1, together with their sources.

General methods. Restriction endonucleases and other enzymes were obtained from Amersham, New England Biolabs or BRL, and were used as recommended by the suppliers. Replicative DNA forms of M13mp9, M13mp10 and M13mpll were obtained from PL Biochemicals (Milwaukee, Wis., USA) or BRL. Preparation of phage $\phi 105$ and its DNA, transduction, and other general phage techniques have been described previously (Jenkinson \& Mandelstam, 1983). The defective transducing phage, $\phi 105 \mathrm{DS} 1$, was provided with wild-type helper phage during transduction (Savva \& Mandelstam, 1984). General cloning techniques, preparation of plasmid DNA, ligation and transformation of Escherichia coli recipients and Southern hybridizations (Southern, 1975) were performed as described elsewhere (Fort \& Piggot, 1984; Errington, 1984).

Cloning in MI3 or pUC vectors in $E$. coli is facilitated by a convenient colour indication of the presence of inserted DNA. Insertion of a target DNA in any one of a range of unique restriction endonuclease cleavage sites clustered in a 'polylinker' region results in the loss of $\beta$-galactosidase (lacZ) activity, which can be detected using the chromogenic indicator, 5-bromo-4-chloro-3-indolyl- $\beta$-D-galactopyranoside (X-gal), as substrate (Messing, 1983).

DNA sequencing. Fragments of spoVA DNA, originally from plasmid pPP33 or phage $\phi 105 \mathrm{DS} 1$, were subcloned in M13mpl0 or M13mpll for sequencing using the chain terminator method of Sanger et al. (1977). A combination of exonuclease III and nuclease SI (Guo et al., 1983) was used to shorten the large (>1.5 kbp) DNA inserts in two plasmid sub-clones, pPF5 and pPF25, before further sub-cloning in M13. Putative recombinant MI3s were analysed by hybridizing the single-stranded phage DNA to DNA from a phage carrying the original

Table 1. Bacterial strains, bacteriophages and plasmids

Bacterial

strains

Genotype

Source/reference

Escherichia coli

HB101

$F^{-}$hsdS20 supE44 supF58 lac Y1 or lacIZY76 galK2 $\}$ galT22 metB1 trpR55

JM103 $\triangle($ lac-pro $)$ thi strA supE end A sbcB15 F' traD36 $\}$ pro $A B$ lacl ${ }^{q} Z \triangle M I 5$

JM105 as JM103, but replace $\sup E$ with $h s d R 4$

Boyer \& Roulland-Dussoix (1969)

Messing et al. (1981)

Messing (1983)

Bacillus subtilis MB75 $\left(\mathrm{Spo}^{+}\right)$

metC3 lys-1 tal-1

spoVA89

570

spoVA570

spoVA57I

spoVA572

spoVA573

hisH2 rpoB2 sul

spoVA574

spoVA575

spoVA576

spoVA89

spoVA570

spoVA571

spoVA572

spoVA573

Clys-l tal-1

Laboratory stock

spoVA574

spoVA575

574.1

575.1

spoVA576

Errington \& Mandelstam (1984)

Errington \& Mandelstam (1984) 
Table 1. (continued)

Bacteriophages

$\left.\begin{array}{l}\text { M13mp9 } \\ \text { M13mp10 } \\ \text { M13mp11 }\end{array}\right\}$

Relevant characteristics

Chain termination sequencing vectors

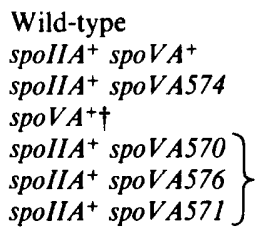

Plasmids

Stock

plasmids

$\begin{array}{lll}\text { pUC13 } & \text { bla } & 2.7 \mathrm{kbp} \\ \text { pSGMU1 } & \text { bla } \text { cat } & 4.7 \mathrm{kbp} \\ \text { pPP33† } & \text { cat tet } & 8.9 \mathrm{kbp}\end{array}$

Source/reference

Messing (1983)

\section{BGSC*}

Savva \& Mandelstam (1984)

S. E. Hartley (unpublished)

Errington (1984)

This paper
Constructed plasmids

pPF5

pPF25

pSGMU2

pSGMU6

pSGMU7

pSGMU8

pSGMU9

pSGMUI0

pSGMU11

pSGMU12
Relevant characteristics

\section{Reference}

Messing (1983)

Errington (1984)

Piggot et al. (1984)

* The Bacillus Genetic Stock Center, Ohio State University, Ohio, USA.

$\dagger$ pPP33 and $\phi 105 \mathrm{~J} 15$ contain the $3.2 \mathrm{kbp} \mathrm{Bg}$ III fragment of wild-type B. subtilis chromosomal DNA which spans the spoIIA and $\operatorname{spoVA}$ loci.

\pm Previously designated pSG1.

$\S$ The vector and the enzymes used to digest it are given first. After the + symbol the size of the inserted DNA fragment is given, followed by the restriction endonuclease(s) used to generate it. The numbers in parentheses refer to the positions of the cleavage sites in the nucleotide sequence in Fig. 3, except for the first PvuII site in pSGMU9, which is located in the adjacent spoIIA locus (see Fort \& Piggot, 1984). The DNA inserts in the plasmids derived from pSGMU2 were subcloned from M13mp9, M13mpl0 or M13mpll as indicated. Some of the DNA inserts were derived by shortening of larger fragments using exonuclease III and nuclease S1 (ExoIII/S1) as described in Methods. The end points of the inserts in plasmids pSGMU11 and pSGMU12 have been determined by sequencing and are $441 \mathrm{bp}$ and $17 \mathrm{bp}$, respectively, beyond the $3^{\prime}$ end of the sequence given in Fig. 3. The former end-point may be within phage-derived sequences (see Results).

full-length insert in reverse orientation. After digestion with nuclease SI, the protected shortened insert was sized on a $1 \%(w / v)$ agarose gel (Poncz et al., 1982). Sequencing reactions were performed according to Sanger et al. (1980) except that gradient buffer gels and ${ }^{35}$ S-labelled nucleotides were sometimes used (Biggin et al., 1983).

Complementation analysis. For complementation analysis, partially diploid $B$. subtilis strains were constructed by infecting spoVA mutant strains with phage $\phi 105$ derivatives carrying cloned portions of the spoVA locus. Mutations in the spoV $A$ locus were transferred onto the $\phi$ l05DSl genome, which carries the complete spoVA locus (Savva \& Mandelstam, 1984; Errington \& Mandelstam, 1984), as follows. A his H2 or lys-l auxotrophic strain carrying a spoVA mutation was transduced with $\phi 105 \mathrm{DS} 1$ by selection for $\mathrm{Spo}^{+}$(see below). The resulting heterozygous $\mathrm{Spo}^{+}$strain was transformed with DNA from a $l y s^{+}$or his ${ }^{+}$donor strain, carrying the same spoVA mutation. Approximately $3 \%$ of the progeny were phenotypically $\mathrm{Spo}^{-}$as a result of recombination between the spoVA mutation on the transforming DNA and its wild-type allele on the $\phi 105 \mathrm{DS} 1$ prophage (a phenomenon known as congression; Dubnau, 1982). 


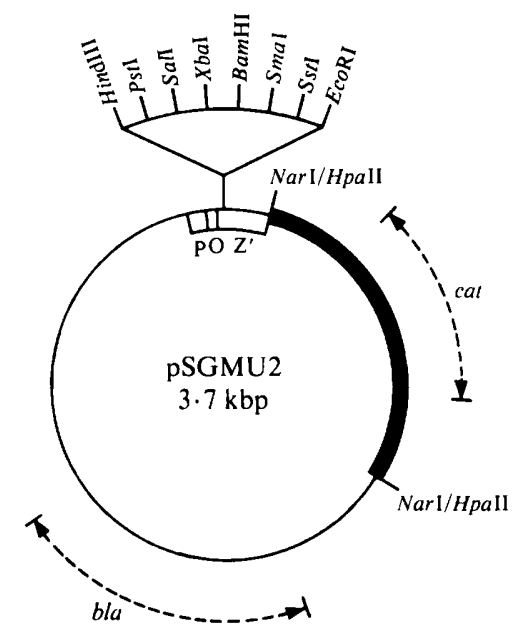

Fig. 1. Structure of plasmid pSGMU2. This plasmid was constructed by cloning a $1.0 \mathrm{kbp} \mathrm{HpaII}$ fragment of DNA containing a selectable chloramphenicol-resistance gene (cat) into the unique NarI site of the E. coli plasmid vector pUC13 (Messing, 1983). The HpaII fragment was obtained from plasmid pSGMUI (Errington, 1984) but originated in the staphylococcal plasmid, pC194 (Iordanescu et al., 1978). The thick and thin lines denote DNA from plasmids pSGMU1 and pUC13, respectively. Plasmid pUC13 carries a selectable gene, bla, which confers ampicillin-resistance in $E$. coli, and a series of unique restriction endonuclease cleavage sites arranged within the coding region of a part of the $\beta$ galactosidase gene $\left(l a c Z^{\prime}\right)$. In suitable $E$. coli hosts a convenient colour test indicates the presence of cloned DNA fragments within the polylinker region.

For complementation analysis, non-lysogenic strains carrying spoVA mutations were grown in Oxoid Penassay Broth to late exponential phase, diluted 10-fold and plated on Schaeffer's agar (Schaeffer $e$ t al., 1965) to give a uniform lawn of cells. Phage lysate $(20 \mu \mathrm{l})$, made up by mixing equal parts of transducing and 'helper' phage lysates, was spotted on to the lawn and allowed to soak in. The plates were incubated for $24 \mathrm{~h}$ at $37^{\circ} \mathrm{C}$, and chloroform vapour was used to select for $\mathrm{Spo}^{+}$transductants (Hoch, 1971). If complementation had occurred, $\mathrm{Spo}^{+}$ lysogenic survivors were apparent within and around the region of lysis caused by the phage infection after further incubation for $2-3 \mathrm{~d}$ at $37^{\circ} \mathrm{C}$.

Construction of plasmid pSGMU2. Plasmid pSGMU1 (Errington, 1984), which carries the chloramphenicolresistance gene originally from plasmid pC194 (Iordanescu et al., 1978), was digested with $B a m \mathrm{HI}$, and the $2.0 \mathrm{kbp}$ DNA fragment containing the chloramphenicol-resistance determinant (cat) was isolated from a low-meltingtemperature agarose gel $(0.6 \%, \mathrm{w} / \mathrm{v}, \mathrm{BRL})$ using the method recommended by the suppliers. The fragment was then digested with $\mathrm{HpaII}$ and ligated into the unique NarI site of plasmid pUC13. The target fragment contains a site for the $E$. coli $E c o K$ restriction system (nucleotides 1092 to 1105 in the published sequence of plasmid pC194; Horinouchi \& Weisblum, 1983), so a restrictionless E. coli strain, HB101, was initially used as recipient. Ampicillin-resistant transformants were screened for resistance to chloramphenicol $\left(15 \mu \mathrm{g} \mathrm{ml}^{-1}\right)$, and one of the resistant clones was isolated. For further cloning experiments plasmid DNA was prepared from $E$. coli strain $\mathrm{JM} 105$, which is also restrictionless but still possesses the EcoK modification system. E. coli strain JM103 (restriction ${ }^{+}$and modification ${ }^{+}$) was subsequently used as recipient because of its higher transformation frequency. The structure of plasmid pSGMU2 is shown in Fig. 1.

Analysis of spoVA transcriptional units by plasmid integration. Suitable DNA inserts from the M1 3 clones used in the sequence determination were sub-cloned in pSGMU2 using their common 'polylinker' restriction sites. About $1 \mu \mathrm{g}$ plasmid DNA was used to transform B. subtilis strain MB75 to chloramphenicol resistance; the selection medium was Oxoid Nutrient Agar containing $5 \mu \mathrm{g}$ chloramphenicol $\mathrm{ml}^{-1}$. Chloramphenicol-resistant transformants occur by integration of the plasmid, which cannot replicate autonomously in $B$. subtilis, into the chromosome.

Transformation and sporulation. Methods for transformation of $B$. subtilis, induction of sporulation and measurement of the incidence of heat-resistant spores have been described previously (Errington \& Mandelstam, 1983, 1984). 


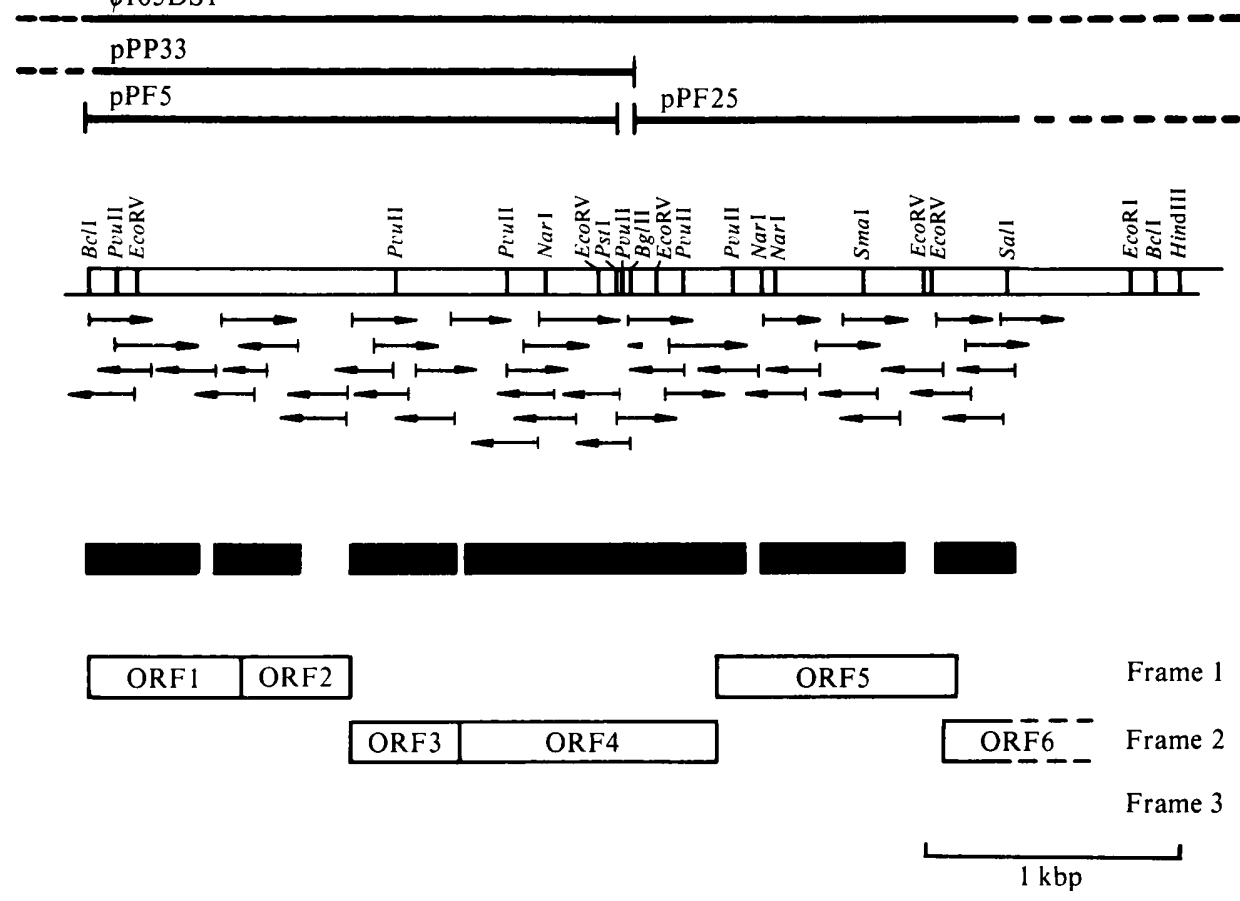

Fig. 2. Sequencing procedure and putative translation products of the spoVA locus. The upper part of the figure shows a physical map of the spoVA locus including some of the restriction endonuclease cleavage sites, as deduced from the nucleotide sequence. Restriction endonuclease cleavage sites to the right of the SalI site were determined by Southern hybridization experiments (see Results and Piggot $e t$ al., 1984). The arrows indicate the direction and extent of individual sequence determinations with the base of each arrow marking the beginning of the sequence ( $5^{\prime}$ end). The solid boxes indicate those areas that were sequenced in both strands; about $80 \%$ of the spoVA locus was sequenced in both directions. Large ORFs in each of the three possible frames, reading left to right, are shown at the bottom of the figure and are labelled as in Tables 2 and 3. At the top of the figure the solid bars indicate the DNA fragments inserted in phage $\phi 105 \mathrm{DS} 1$, plasmid pPP33 and two plasmid sub-clones that were used in the sequencing.

\section{RESULTS}

\section{Determination of the sequence}

The sources of DNA for sequencing were a $3.3 \mathrm{kbp} \mathrm{BglII} \mathrm{fragment} \mathrm{contained} \mathrm{in} \mathrm{plasmid}$ pPP33 (Piggot et al., 1984) and a $7 \mathrm{kbp}$ HindIII fragment contained in phage $\phi 105 \mathrm{DS} 1$ (Savva \& Mandelstam, 1984), as shown in Fig. 2. Plasmids pPF25 and pPF5 were isolated by sub-cloning the $2.0 \mathrm{kbp} B g / \mathrm{II}-H i n d I I I$ fragment from $\phi 105 \mathrm{DS} 1$ and the $2.15 \mathrm{kbp} \mathrm{BclI}-P$ st I fragment from plasmid pPP33, respectively, into plasmid pUC13 (Fig. 2). The inserts in these plasmids were shortened progressively from each end in turn, using exonuclease III and nuclease S1, and were sub-cloned into M13mpl0 or M13mpll as appropriate. The sequencing data obtained were analysed on a computer using the DB system of Staden (1982) to arrange the overlapping sequence determinations into continuous units. In addition, the $1.54 \mathrm{kbp} \mathrm{PstI-SalI}$ fragment from $\phi 105 \mathrm{DS} 1$ was sequenced from its $P$ st I end to read through the $B g / \mathrm{II}$ site, and the $2.29 \mathrm{kbp}$ $B c l$ I-HindIII fragment from pPP33 was sequenced from its HindIII end (within vector sequences) to read through the PstI site. Other data were obtained by sequencing $P v u \mathrm{II}$ fragments sub-cloned from $\phi 105 \mathrm{DS} 1$ and a $\mathrm{NarI}-\mathrm{Bg} / \mathrm{II}$ fragment from pPF25. The completed sequence of $3706 \mathrm{bp}$ is shown in Fig. 3, and the sequencing procedure in Fig. 2. About $80 \%$ of the sequence was determined in both directions; regions sequenced on only one strand were determined from the readings of at least two overlapping $\mathrm{M} 13$ clones. The sequence begins at a $B c l$ I site that represents one end of the nucleotide sequence of a DNA segment containing the spoIIA locus that was published previously (Fort \& Piggot, 1984), and ends at a SalI site. 
M M M E R R

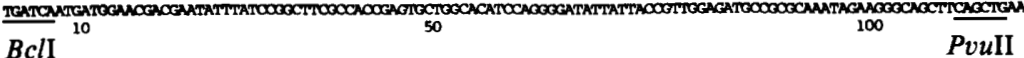

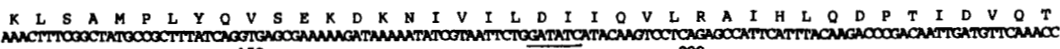
150 EcoR V

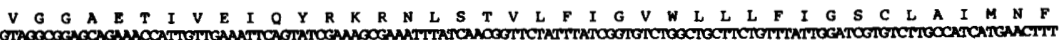
250

H E E V V S S M 400 450

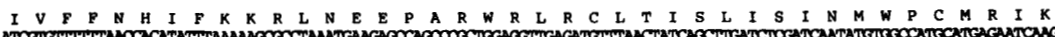

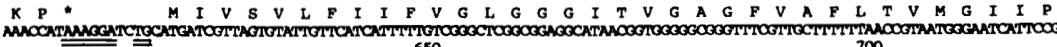
650 700

R L M O L T K T M R F V O A Y E E A A V I I L G A V C G G W E T L

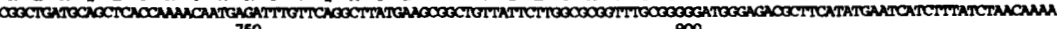

W I A $V$ V P $V$ V G B50 900

I I I L L M A I V I G K I A G S L F H W L

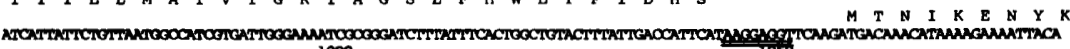

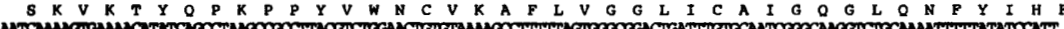
1100 1150

1200

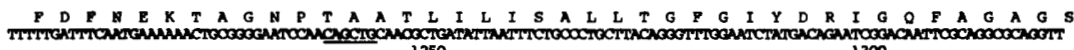
PvuII

A V P V T G F A N S M A S A A L E Y X S E G L V L G V A T N M F K L A G N V I V

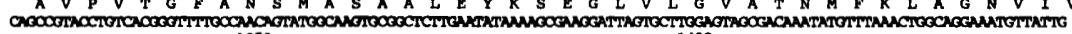
$1350 \quad 1400$

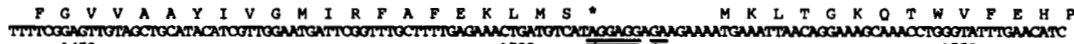
1450 1500

I F V N S A A G T A A A G P K E K K D G 160021650

E R O L M E D A V N V A L O K N N L T K D D I D L L L L A G D L L L N O N

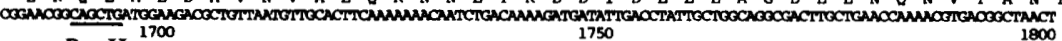
PvuII 1700

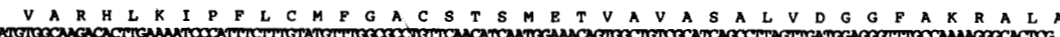

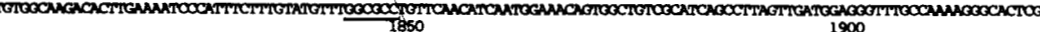
NarI

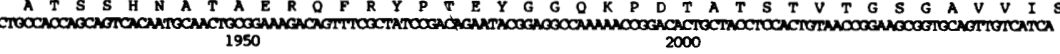

$\begin{array}{cccccccccccccccccccccccccccccccccccccccccc}Q & T & P & G & D & I & Q & I & T & S & A & T & V & G & K & V & S & D & L & G & I & T & D & P & F & D & M & G & S & A & M & A & P & A & A & A & D & T & I & K\end{array}$
2050
EcoR V 2100
PstI PvuII

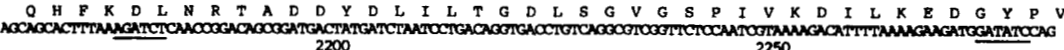
BglII 2200 2250

EcoR V

G $T$ T K H

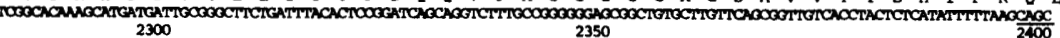
PvuII

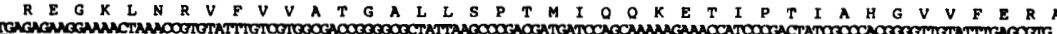
2450 2500

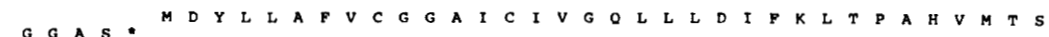

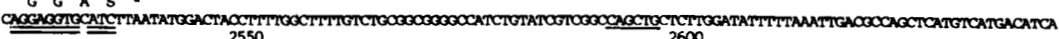
PvuII

$\begin{array}{lllllllllllllllllllllllllllllllllllllllll}F & V & V & I & G & A & I & L & D & G & F & G & I & Y & D & K & F & I & E & F & A & G & G & G & A & I & V & P & I & V & S & F & G & H & S & L & L & H & G & A\end{array}$ 2650 
Fig. 3 (continued)

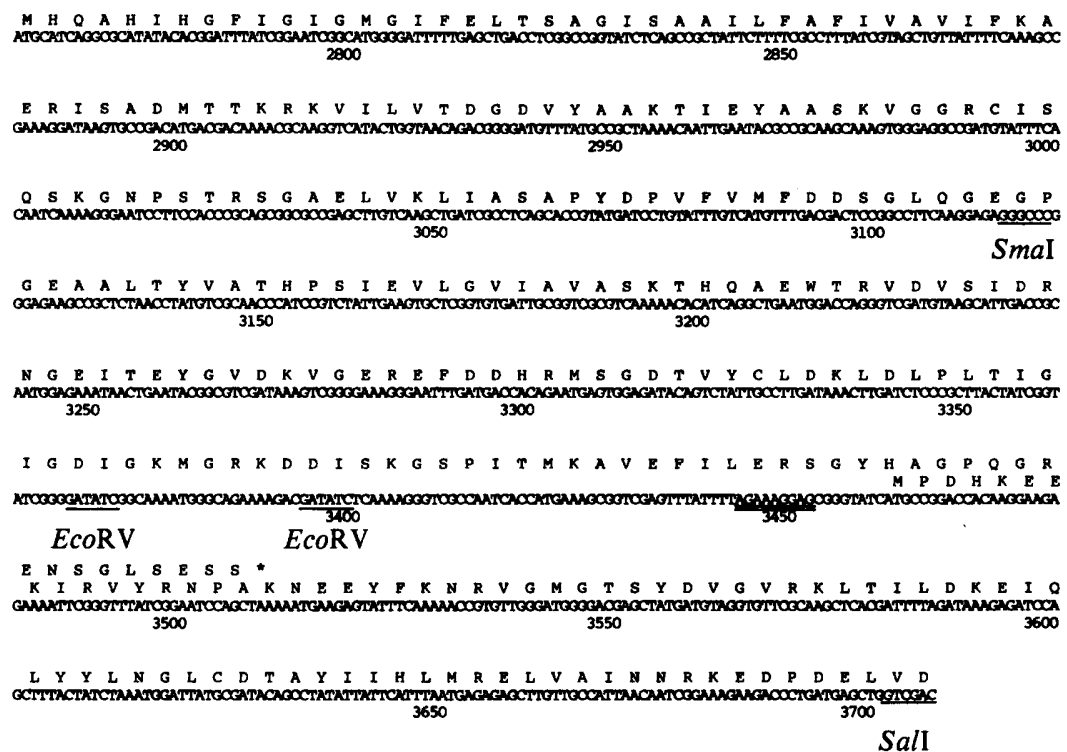

Fig. 3. Nucleotide sequence of the spoVA region. The sequence was determined from sub-clones of plasmid pPP33 (Piggot et al., 1984) and phage $\phi 105$ DS1 (Savva \& Mandelstam, 1984). Restriction sites used for sub-cloning are underlined and the putative ribosome binding sites are doubly underlined. Above the nucleotide sequence the predicted translation products are given using standard one-letter amino-acid abbreviations.

Analysis using integrational plasmids (see below) suggested that the essential part of the spoVA transcriptional unit was contained within the region sequenced. However, Southern hybridization experiments showed that the distal part of the $7 \mathrm{kbp}$ HindIII fragment in $\phi 105 \mathrm{DS} 1$, i.e. the region beyond the SalI site, contained some phage DNA sequences (data not shown). Presumably the deletion that occurred during the isolation of $\phi 105 D S 1$ (Savva \& Mandelstam, 1984) extended into the chromosomal DNA insert. This would also explain the small discrepancy between the restriction maps of the region presented previously (Piggot $e$ t al., 1984; Savva \& Mandelstam, 1984). To confirm that the sequenced region was composed of chromosomal DNA and not phage sequences, plasmid pSGMU12 DNA (see below) was ${ }^{32} \mathrm{P}$ labelled and used as a probe in Southern hybridizations with restriction fragments of chromosomal DNA (B. subtilis strain MB75) and phage $\phi 105 \mathrm{DI}$ : 1t DNA, the vector from which $\phi 105 D S 1$ was derived. The labelled probe hybridized to a BglII-SalI fragment of chromosomal DNA of the expected size $(1.5 \mathrm{kbp})$ but it did not hybridize to $\phi 105 \mathrm{DI}: 1 \mathrm{t}$ DNA (data not shown).

\section{Analysis of gene products and regulatory signals}

Evidence described below shows that the spoVA locus is likely to be transcribed as a single polycistronic mRNA and that the sequence given in Fig. 3 is likely to be the sense strand. Analysis of the sequence using the RUTRANSQ program of Staden (1977) showed six large ORFs covering most of the sequenced region (Figs 2 and 3). Each of the ORFs starts with an ATG codon, which is preceded by a putative ribosome binding site (Shine \& Dalgarno, 1974). The free energy values for base-pairing between the putative ribosome binding sites and the $3^{\prime}$ end of the 16S rRNA of $B$. subtilis are given in Table 2, the first site being taken from the previously determined sequence of the spoIIA region (Fort \& Piggot, 1984). The $\Delta G$ values calculated (Tinoco et al., 1973) fall within the range $-12.0 \mathrm{kcal} \mathrm{mol}^{-1}$ (ORF 2) to $-22.0 \mathrm{kcal}$ $\mathrm{mol}^{-1}$ (ORF5). These are in the same range as those reported for other $B$. subtilis ribosome binding sites (Moran et al., 1982). The first five ORFs are non-overlapping and each terminates 
Table 2. Putative ribosome binding sites preceding spoVA ORFs

Free energies of base pairing $(\Delta G)$ between putative ribosome binding sites (see Fig. 2) and the $3^{\prime}$ terminus of the $B$. subtilis 16S ribosomal RNA (McLaughlin et al., 1981) were determined using the rules described by Tinoco et al. (1973).

\begin{tabular}{lccc}
\multicolumn{1}{c}{ Position* } & \multicolumn{1}{c}{ Sequence ${ }^{\dagger}$} & $\Delta G\left(\mathrm{kcal} \mathrm{mol}^{-1}\right) \ddagger$ & ORF \\
$2060 \S$ & GAAAG - A t TGATC & $-14 \cdot 6$ & 1 \\
608 & AAAGGA c TG & $-12 \cdot 0$ & 2 \\
1043 & AAGGAGGT & $-20 \cdot 0$ & 3 \\
1507 & AGGAGGaGA & $-16 \cdot 8$ & 4 \\
2532 & AGGAGGTG A TC & $-22 \cdot 0$ & 5 \\
3444 & AGAAAGGAG & -18.4 & 6 \\
16 S rRA & UCUUUCCUCCACUAG-3'-OH &
\end{tabular}

\footnotetext{
* Number of the first nucleotide in the given sequence, with reference to Fig. 3 .

+ Nucleotides complementary to the $3^{\prime}$ terminus of the 16S rRNA are shown in upper case. $\ddagger 1 \mathrm{cal}=4 \cdot 184 \mathrm{~J}$.

$\S$ Taken from the sequence presented by Fort \& Piggot (1984).
}

Table 3. Properties of putative spoVA translation products

$\begin{array}{lrrcccc} & \overbrace{\text { Start }}^{\text {Position* }} & \text { Stop } & \begin{array}{c}\text { Number of } \\ \text { amino acids }\end{array} & \begin{array}{c}10^{-3} \times \\ \text { Mol. wt }\end{array} & \text { pI† } & \begin{array}{c}\text { Polarity } \\ \text { index }\end{array} \\ \text { ORF1 } & 7 & 606 & 200 & 23 \cdot 1 & 10 \cdot 4 & 40 \\ \text { ORF2 } & 619 & 1041 & 141 & 15 \cdot 2 & 10 \cdot 8 & 23 \\ \text { ORF3 } & 1056 & 1505 & 150 & 16 \cdot 1 & 10 \cdot 2 & 32 \\ \text { ORF4 } & 1521 & 2534 & 338 & 36 \cdot 0 & 5 \cdot 4 & 45 \\ \text { ORF5 } & 2539 & 3507 & 323 & 34 \cdot 3 & 5 \cdot 5 & 38\end{array}$

* First nucleotide of start codon and last nucleotide before stop codon from Fig. 3.

$\dagger$ Predicted isoelectric point calculated as described by Martin (1964).

$\ddagger$ Determined using the MWCALC program of Staden \& McLachlan (1982).

at or near the ribosome binding site of the following gene. The sixth ORF overlaps the fifth by about $50 \mathrm{bp}$ and extends beyond the region sequenced. The molecular weights and predicted isoelectric points of the putative proteins encoded by ORFs 1 to 5 are shown in Table 3 . No ORFs large enough to encode a protein of molecular weight $>5000$ were apparent in the presumed antisense strand.

Data from 'Northern' hybridizations using a spoVA-specific DNA probe suggests that the spoVA mRNA initiates within the region between the spoIIA and spoVA ORFs (D. Savva, unpublished resuits). However, a search of the nucleotide sequence of this region revealed no extensive homologies to known $B$. subtilis promoter sequences. The same region contains a possible termination signal for transcription of the spoIIA operon (nucleotides 1770 to 1794 in the nucleotide sequence presented by Fort $\&$ Piggot, 1984), but no such signals are apparent in the presumptive coding strand of the spoVA nucleotide sequence.

\section{Complementation analysis}

Since the nucleotide sequence suggested that the spoVA locus was polycistronic, it was unlikely that all of the eight previously characterized spoVA mutations (Errington \& Mandelstam, 1984) would be found to lie in the same gene. To test this prediction, derivatives of phage $\phi 105$ carrying cloned fragments of spoVA DNA were used to make partially diploid strains for complementation analysis. $\phi 105 D S 1$ (Savva \& Mandelstam, 1984) carries a $7 \mathrm{kbp}$ DNA fragment that complements all of the known spoVA mutations (Errington \& Mandelstam, $1984)$ and also mutations in the adjacent spoIIA locus. Phages $\phi 105 \mathrm{SH} 3, \phi 105 \mathrm{~J} 16, \phi 105 \mathrm{~J} 17$ and $\phi 105 \mathrm{~J} 18$ were constructed by transferring mutations $574,570,576$ and 571 respectively on to the $\phi 105 D S 1$ genome as described in Methods. In each case the genotype was verified by showing that the phage was unable to transduce to $\mathrm{Spo}^{+}$strains carrying the same spoVA mutation but had retained the ability to transduce to $\mathrm{Spo}^{+}$a strain carrying the spoIIA69 mutation. 


\section{Table 4. Complementation analysis of spoVA mutations}

A bacterial strain carrying a mutation in the $\operatorname{spo} A A$ locus was transduced with phage carrying the same or a different spoVA mutation. Complementation was indicated by the appearance of numerous survivors (phenotypically $\mathrm{Spo}^{+}$) following selection for $\mathrm{Spo}^{+}$transductants. The order of the mutations across the table is as determined in three-factor transformation crosses (Errington \& Mandelstam, 1984). + , Transduction of recipient to $\mathrm{Spo}^{+}$by phage; - , no tranduction of recipient strain to $\mathrm{Spo}^{+}$; $(+), \mathrm{Spo}^{+}$colonies appeared at low frequency $\left(10^{-4}\right.$ per survivor of phage infection; see Results).

\begin{tabular}{|c|c|c|c|c|c|c|c|c|c|}
\hline \multirow[b]{2}{*}{$\begin{array}{c}\text { Transducing } \\
\text { phage }\end{array}$} & \multirow[b]{2}{*}{$\begin{array}{l}\text { spoVA mutation } \\
\text { carried by phage }\end{array}$} & \multicolumn{8}{|c|}{ spoVA mutation carried by recipient: } \\
\hline & & $\overparen{574}$ & 575 & 571 & 572 & 570 & 573 & 89 & 576 \\
\hline$\phi 105 \mathrm{DS} 1$ & None & + & + & + & + & + & + & + & + \\
\hline$\phi 105 \mathrm{SH} 3$ & 574 & - & - & + & - & + & + & + & + \\
\hline$\phi 105 \mathrm{~J} 18$ & 571 & + & - & - & - & + & + & + & + \\
\hline$\phi 105 \mathrm{~J} 16$ & 570 & + & + & + & - & - & - & + & + \\
\hline$\phi 105 \mathrm{~J} 17$ & 576 & + & + & + & + & + & + & - & - \\
\hline$\phi 105 \mathrm{~J} 15$ & None* & + & + & + & $(+)$ & $(+)$ & - & - & - \\
\hline
\end{tabular}

* This phage carries a chromosomal DNA insert that comprises only part of the spoVA locus (see text).

Strains carrying each of the eight characterized spoVA mutations were transduced in turn with each of the phage stocks described above. The results of subsequent $\mathrm{Spo}^{+}$selections are shown in Table 4. Six of the mutations could be sub-divided unambiguously into four complementation groups, denoted by square brackets, as follows: [574]; [571]; [570, 573]; [89, 576]. Two mutations showed anomalous complementation patterns. Mutation 575 was not complemented by $\phi 105 \mathrm{SH} 3$ or $\phi 105 \mathrm{~J} 18$, carrying mutations 574 and 571 respectively, although the latter mutations clearly complement each other. Mutation 572 was complemented by $\phi 105 D S 1$ and $\phi 105 \mathrm{~J} 17$ but not by any of the other phages.

To confirm that the $\mathrm{Spo}^{+}$phenotype of transductants was due to complementation and not recombination, DNA was extracted from several independent $\mathrm{Spo}^{+}$clones and used to transform strain MB75. In each case about $30 \%$ of the $\mathrm{Lys}^{+}$transformants displayed a SpoVA ${ }^{-}$ phenotype (data not shown). This indicates that the $\mathrm{Spo}^{+}$transductants still contained a chromosomal spoVA mutation and hence that complementation was responsible for the observed phenotype.

Phage $\phi 105 \mathrm{~J} 15$ was isolated from a $B$. subtilis genomic library constructed by cloning chromosomal DNA fragments generated by cleavage with $B g l \mathrm{II}$ into the unique BamHI site of $\phi 105 \mathrm{~J} 9$ (Errington, 1984). This phage, which carries a $3.3 \mathrm{kbp}$ insert, was isolated on the basis of complementation of the spoVA574 mutation and, unlike $\phi 105 \mathrm{DS} 1$ and its derivatives, it is able to plaque and lysogenize normally. Consequently, all of the survivors of infection with this phage are phenotypically $\mathrm{Spo}^{+}$. Only the first two groups of mutations were complemented by this phage. Two additional mutations, 570 and 572 , though not complemented, appeared to be rescued by recombination; the majority of cells that survived infection remained $\mathrm{Spo}^{-}$but a small number of $\mathrm{Spo}^{+}$survivors (about $10^{-4}$ per survivor) were always present.

\section{Use of integrational plasmids to define the transcriptional unit(s) of the spoVA locus}

Since the nucleotide sequence contained six putative proteins but only four complementation groups were defined, it was important to determine whether all six ORFs encoded proteins that were essential for sporulation, and, if so, whether they were transcribed as a single unit. One method of determining the extent of a transcriptional unit is to use integrational plasmids, as described by Piggot et al. (1984) for the spoIIA operon. The method depends upon the use of a plasmid with two salient properties: firstly, the ability to replicate autonomously in $E$. coli but not in $B$. subtilis; secondly, the expression of an antibiotic resistance gene, in this case $\mathrm{Cm}^{\mathrm{R}}$, that can be selected in $B$. subtilis. Although such a plasmid is incapable of replicating autonomously in B. subtilis, $\mathrm{Cm}^{\mathrm{R}}$ transformants can be obtained if it contains a fragment of DNA that has homology with the $B$. subtilis chromosome. Such plasmids have been shown to integrate into the recipient chromosome by a Campbell-like mechanism (i.e. by a single crossover event) that 

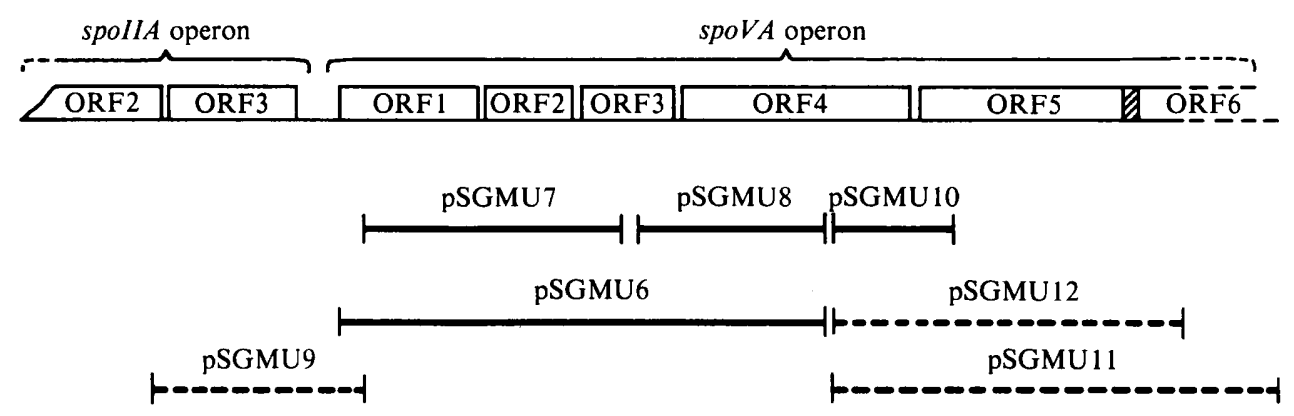

Fig. 4. Analysis of spoVA transcriptional units using integrational plasmids. The upper part of the figure shows a physical map of the spoVA region (see Fig. 3) and the adjacent spoIIA region (Fort \& Piggot, 1984). Below, the fragments of DNA subcloned in the integrational plasmid, pSGMU2, are shown with the designations of the derivative plasmids given. Solid lines indicate that the integration of the plasmid into the chromosome of $B$. subtilis strain $\mathrm{MB} 75\left(\mathrm{Spo}^{+}\right)$resulted in a SpoVA phenotype (see Table 5) whereas dotted lines indicate that the phenotype remained $\mathrm{Spo}^{+}$.

results in duplication of the homologous DNA insert on each side of the inserted plasmid sequence (Duncan et al., 1978; Haldenwang et al., 1980). The consequences of such an insertion depend upon the end points of the homologous DNA in the original plasmid. If both ends are within a functional transcription unit that is essential for sporulation, insertion will result in a $\mathrm{Spo}^{-}$phenotype. However, if one or both ends of the insert extend beyond the essential part of the functional unit, the $\mathrm{Spo}^{+}$phenotype will be retained.

A versatile integration plasmid, pSGMU2, was constructed as described in Methods. In addition to the properties described above, it carries unique sites for a number of restriction endonucleases, and gives a convenient colour test for the identification of recombinant clones.

Various restriction fragments, some shortened by treatment with exonuclease III and nuclease $\mathrm{S} 1$ and used in the nucleotide sequencing, were sub-cloned from phage M13 into plasmid pSGMU2. The size of the DNA insert in each of these pSGMU2 derivatives was checked by restriction analysis and the extent of the homologous insert in each plasmid is shown in Fig. 4. About $1 \mu \mathrm{g}$ of DNA from each of these plasmids was used to transform $B$. subtilis strain $\operatorname{MB} 75\left(\mathrm{Spo}^{+}\right)$and in each case between $10^{2}$ and $10^{3}$ chloramphenicol-resistant progeny were obtained. The transformants from any one cross were phenotypically homogeneous, being either wild-type or typically SpoVA- as judged by microscopic examination of colonies after $5 \mathrm{~d}$ on chloramphenicol-containing agar at $37^{\circ} \mathrm{C}$. The phenotype of each class of transformant was tested more rigorously by inducing sporulation in liquid medium, in the presence of chloramphenicol, and assaying the number of heat-resistant spores at $t_{9}$. The values for heatresistant spores (Table 5) were in complete accordance with the results obtained by microscopic examination. The low incidence of spores seen in the transformants recognized as SpoVA- was mainly due to spontaneous reversal of integration, which would remove the block on transcription. In support of this explanation was the observation that $>90 \%$ of the heatresistant survivors were found to have become both chloramphenicol-sensitive and $\mathrm{Spo}^{+}$(data not shown). Integration of plasmids pSGMU9, pSGMU11 and pSGMU12 did not produce a SpoVA ${ }^{-}$phenotype, indicating that at least one end of the homologous inserts in each of these plasmids extends beyond the essential part of the spoVA operon.

Southern hybridizations were used to confirm that integration of the pSGMU2 derivatives occurred by the expected Campbell mechanism. Chromosomal DNA, extracted from strain MB75 and a derivative containing plasmid pSGMU10 in the integrated form, was restricted with $P s t \mathrm{I}$ or $B g l \mathrm{II}$, transferred to nitrocellulose and probed with labelled DNA from plasmid pSGMU10. With both enzymes the hybridization pattern was consistent with the integration of two copies of plasmid pSGMU10, in tandem, by a Campbell-like mechanism (data not shown). The occurrence of tandem duplication of an integrational plasmid has been reported by other authors (Young, 1983; Piggot et al., 1984). We assume, although it has not been established experimentally, that the other pSGMU2 derivatives, including pSGMU9, pSGMU11 and pSGMU12, have integrated by a Campbell-like mechanism. 
Table 5. Analysis of spoVA transcriptional units using integrational plasmids

DNA (about $1 \mu \mathrm{g}$ ) from derivatives of the integration plasmid, pSGMU2, carrying inserts of spoVA DNA (Fig. 4) was used to transform B. subtilis strain $\mathrm{MB} 75\left(\mathrm{Spo}^{+}\right)$with selection for chloramphenicolresistance. Cells from a single isolated chloramphenicol-resistant colony in each cross were induced to sporulate in liquid medium containing chloramphenicol, and the production of heat-resistant spores was determined on non-selective media.

$\begin{array}{llc}\text { Plasmid } & \text { Phenotype* }^{*} & \begin{array}{c}\text { Heat-resistant } \\ \text { spores } \mathrm{ml}^{-1}\left(t_{9}\right)\end{array} \\ \text { pSGMU6 } & \text { SpoVA }^{-} & 4.4 \times 10^{4} \\ \text { pSGMU7 } & \text { SpoVA }^{-} & 3.2 \times 10^{4} \\ \text { pSGMU8 } & \text { SpoVA }^{-} & 4.4 \times 10^{4} \\ \text { pSGMU9 } & \text { Spo }^{+} & 4.9 \times 10^{8} \\ \text { pSGMU10 } & \text { SpoVA }^{-} & 1.6 \times 10^{4} \\ \text { pSGMU11 } & \text { Spo }^{+} & 2.6 \times 10^{8} \\ \text { pSGMU12 } & \text { Spo }^{+} & 4.7 \times 10^{8}\end{array}$

* As judged by phase contrast microscopy of sporulating cells.

\section{DISCUSSION}

The nucleotide sequence of a 3706 bp DNA segment encoding the spoVA locus is presented in Fig. 3. The $B c l$ I site at the beginning of the sequence marks a 6 bp overlap with the $3^{\prime}$ end of the nucleotide sequence presented previously for a segment of DNA encoding the spoIIA locus (Fort \& Piggot, 1984).

The first five ORFs in the spoVA locus are all closely coupled; each coding region begins very near to the termination signal of the preceding region. The beginning of the sixth ORF overlaps the fifth by about 50 nucleotides. The reason for this difference is not clear but a similar, although less extensive, overlap has been described for the $B$. subtilis trpD and $\operatorname{trp} C$ genes (Band et al., 1984).

The organization of the spoVA ORFs suggest that they constitute a polycistronic operon. We attempted to demonstrate this by making use of integrational plasmids, as described by Piggot $e t$ al. (1984) (see Results). The results presented in Table 4 and summarized in Fig. 3 suggest that ORFs 1 to 5 form a single transcriptional unit. Insertions beginning before ORF1 (pSGMU9) or after ORF5 (pSGMU11 and pSGMU12) give a Spo ${ }^{+}$phenotype (as judged by the formation of heat-resistant spores and by microscopic examination) upon integration, and therefore have at least one end outside the essential part of the transcriptional unit. All of the other integrational plasmids conferred a typical SpoVA phenotype upon integration. It remains possible that an increase in gene dosage was responsible for the observed SpoVA phenotype with some integrated plasmids. However, it seems unlikely, in the case of pSGMU10 at least, that two copies of the integrated plasmid would have this effect. Since plasmid pSGMU9 contains a chromosomal DNA insert that overlaps both spoIIA and spoVA sequences and since it does not disrupt the expression of either upon integration, these operons must be transcribed separately (see also Piggot et al., 1984). The nature of ORF6 may not be clarified until the nucleotide sequence beyond the SalI site is determined unambiguously. This may require cloning a neighbouring chromosomal DNA fragment, perhaps by 'chromosome walking'. It is possible that ORF6 is not actually translated in vivo, or that the absence of its product does not confer an obvious $\mathrm{Spo}^{-}$phenotype. For example, it might encode one of the presumably non-essential biochemical marker events that occur at specific stages during sporulation (Mandelstam, 1976), or it could be involved in spore germination or outgrowth. Alternatively, ORF6 may be expressed as an independent overlapping transcriptional unit from a promoter, as yet unidentified, within the spoVA operon.

The use of the plasmid pSGMU2 may have some advantages in comparison with the integrational plasmids that have been described previously (for example, pJH101, Ferrari et al., 1983; pJAB1, Piggot et al., 1984). It is particularly versatile because of its polylinker cloning region, with unique sites for a range of restriction endonucleases, and a convenient colour reaction that indicates the presence of inserted DN.A. Moreover, the polylinker in pSGMU2 is 
identical to those of bacteriophages M13mp10 and M13mp11, which facilitates the rapid subcloning and testing of DNA fragments characterized by sequencing.

Since the spoVA locus appears to be transcribed as a single mRNA, the promoter for this transcriptional unit must lie to the left of ORF1 (as shown in Figs 2 and 4) if it is to be compatible with the direction of translation and with the direct complementation of some spoVA mutations by phage $\phi 105 \mathrm{~J} 15$. This phage carries a fragment of DNA that extends from a $B g l \mathrm{II}$ site within the spoIIA locus through spoVA ORFs 1, 2 and 3, to a second $B g l$ II site within ORF4. However, the region between the spoIIA and spoVA loci (about 300 nucleotides) contains no sequences strongly homologous to any of the known $B$. subtilis promoter sequences.

Although some, at least, of the stage 0 loci are probably monocistronic, several of the later spo loci have been shown by complementation analysis and/or sequencing to contain more than one gene: spoIVC (Dancer \& Mandelstam, 1981) and spoIVF (Lamont, 1984) both contain at least two genes; spoIIA contains three (Fort \& Piggot, 1984). Here we have identified at least five and possibly six genes in the spoVA locus.

Six of the eight spoVA mutations previously mapped by genetic means and found to have similar phenotypic effects (Errington \& Mandelstam, 1984) have been unambiguously divided into at least four different complementation groups (Table 4). In each case mutations in the same complementation group occupy adjacent positions in the genetic map (Errington \& Mandelstam, 1984). It is not yet possible to assign the four complementation groups to their respective ORFs with certainty. However, mutations 570 and 573 are probably located in ORF4; although they were not complemented by phage $\phi 105 \mathrm{~J} 15$, one of them, 570 , appeared to be rescued by recombination between the insert in this phage and the chromosome. Presumably 570 lies to the left and 573 to the right of the BgllI site in ORF4. If this assumption is correct, mutations 576 and 89 , which map to the right of 570 and 573 (see Table 4) are probably located in ORF5 since ORF6, the only alternative, appears not to be essential for the formation of heatresistant spores (see above). The other complementation groups cannot yet be assigned to the remaining three ORFs with certainty.

Two of the spoVA mutations, 572 and 575 could not be assigned to single complementation groups. Genetic crosses (Errington \& Mandelstam, 1984) suggested unambiguous locations for both of these mutations on a linear map. The most likely explanation for the anomalous complementation results (Table 4) is that strains 572 and 575 contain more than one lesion in the spoVA region, which is always a possibility after mutagenesis with $N$-methyl- $N^{\prime}$-nitro- $N$ nitrosoguanidine (Hopwood, 1970). Determination of the nucleotide sequence of spoVA DNA from these strains should afford an explanation.

Three methods have been described previously for complementation analysis of sporulation genes, but all have inherent drawbacks. Strains carrying the trpE26 marker contain extensive rearrangements of the $B$. subtilis chromosome, one end of which lies within the trp gene cluster (Trowsdale \& Anagnostopoulos, 1975). When such strains are transformed or transduced to $\mathrm{Trp}^{+}$the progeny are unstable $\operatorname{trp}^{+} / \operatorname{trpE26}$ heterogenotes that are partially diploid for a considerable part of the chromosome. This system was used by Karmazyn et al. $(1972,1973)$ and by D. A. Broadbent (cited by Piggot \& Coote, 1976) to study the dominance relationships of several sporulation mutations. However, the method is difficult and the analysis of results is time consuming. It does not seem to have been used subsequently to test complementation between pairs of spo mutants. The protoplast fusion method cannot be used for mutants blocked before stage III, and though complementation was obtained with all stage IV mutants only one stage V mutant, spoVF, was complemented (Dancer \& Mandelstam, 1981). Plasmid complementation analysis depends upon the use of $\mathrm{Rec}^{-}$strains, which are not easy to construct, and difficulties can arise from the increase in gene dosage that occurs with multi-copy plasmids (Kawamura et al., 1981; Banner et al., 1983). In contrast, complementation analysis using $\phi 105$ is relatively easy, particularly in the light of the recent advances in cloning procedures described for this phage (Errington, 1984). The phage provides a single copy system for constructing partial diploids that is stable even in a $\mathrm{Rec}^{+}$background.

The proteins predicted from the nucleotide sequence of spoVA are unusual in several respects. Those encoded by ORFs 1,2 and 3 have calculated isoelectric points that are rather high $(>9 \cdot 0)$. 
A comparison of the amino acid compositions of these basic proteins with those of the acidsoluble spore-specific proteins (Johnson \& Tipper, 1981) showed no obvious similarities. One possible role for such basic proteins would be in binding to DNA for purposes of genetic regulation or for protection during dormancy. The protein product predicted from ORF2 is also very hydrophobic (polarity index 23), and several of the other proteins, particularly that encoded by ORF5, have long tracts (10 or more) of hydrophobic residues, although they are less hydrophobic overall than ORF2. This could indicate that the proteins involved form associations with the membrane or with each other. The similarities of the phenotypic consequences of mutations in different spoVA genes would favour the idea that the proteins are functionally related, perhaps as sub-units of a single protein.

The data base provided by the sequencing of the spoIIA and spoVA loci, together with various vegetative genes such as that for $\alpha$-amylase (Yang et al., 1983) and the tryptophan operon (Band et al., 1984), enabled a comparison of codon usage in vegetative and sporulation-specific genes to be made, but no notable differences were observed (results not shown). This makes it unlikely that the regulation of sporulation genes is effected at the translational level by the appearance of novel species of transfer RNA.

The identification of at least four essential sporulation genes that are probably coordinately regulated as a single operon leads to a problem in nomenclature that is also applicable to the spoIVC, spoIIA and spoIVF loci. The classical nomenclature of spo mutations in terms of genetic loci (Piggot \& Coote, 1976) leaves no obvious place for an extra character with which to distinguish different genes within the same locus. To conform with the proposals of Demerec et al. (1966), we propose that an extra upper case italicized letter to indicate the gene should be included immediately after the letter defining the particular locus and preceding the allele number of the mutation. Although we identified only four distinct genes in terms of complementation groups, the nucleotide sequencing data suggests that there are at least five structural genes within the spoVA operon. We therefore propose that ORFs 1 to 5 correspond to genes that we designate spoVAA, spoVAB, spoVAC, spoVAD and spoVAE, respectively. Some of the mutations have been assigned unambiguously to their respective ORFs (see above). These we have therefore redesignated as follows: spoVAD570, spoVAD573, spoVAE89 and spoVAE576. Until such time as the remaining mutations have been unambiguously assigned to a particular gene (ORF), a hyphen will be included within their designations, e.g. spoVA-574, again as suggested by Demerec et al. (1966).

We are indebted to Professor J. Mandelstam for advice and for many helpful discussions. We also thank J. Rees for help with the computer analysis of data and Miss S. H. Hartley for providing phage $\phi 105 \mathrm{SH} 3$. J. E. acknowledges the expert technical assistance of Ms G. P. Roberts. This work was supported by grants from the Science and Engineering Research Council and Elf Aquitaine (UK).

\section{REFERENCES}

Band, L., Shimotsu, H. \& Henner, D. J. (1984). Nucleotide sequence of the Bacillus subtilis trpE and trpD genes. Gene 27, 55-65.

Banner, C. D. B., Moran, C. P., JR \& Losick, R. (1983). Deletion analysis of a complex promoter for a developmentally regulated gene from Bacillus subtilis. Journal of Molecular Biology 168, 351-365.

Biggin, M. D., Gibson, T. J. \& Hong, G. F. (1983). Buffer gradient gels and ${ }^{35} \mathrm{~S}$ label as an aid to rapid DNA sequence determination. Proceedings of the National Academy of Sciences of the United States of America 80, 3963-3965.

Boyer, H. W. \& Roulland-Dussoix, D. (1969). A complementation analysis of the restriction and modification of DNA in Escherichia coli. Journal of Molecular Biology 41, 459-472.

Dancer, B. N. \& Mandelstam, J. (1981). Complementation of sporulation mutations in fused proto- plasts of Bacillus subtilis. Journal of General Microhiology 123, 17-26.

Demerec, M., Adelberg, E. A., Clark, A. J. \& Hartman, P. E. (1966). A proposal for a uniform nomenclature in bacterial genetics. Genetics 54, 6176.

Dubnau, D. (1982). Genetic transformation in BacilIus. In The Molecular Biology of the Bacilli, vol. 1, pp. 147-178. Edited by D. A. Dubnau. New York \& London: Academic Press.

Duncan, C. H., Wilson, G. A. \& Young, F. E. (1978). Mechanism of integrating foreign DNA during transformation of Bacillus subtilis. Proceedings of the National Academy of Sciences of the United States of America 75, 3664-3668.

ERRINGTON, J. (1984). Efficient Bacillus subtilis cloning system using bacteriophage vector $\phi 105 \mathrm{~J} 9$. Journal of General Microbiology 130, 2615-2628. 
ERrington, J. \& Mandelstam, J. (1983). Variety of sporulation phenotypes resulting from mutations in a single regulatory locus, spollA, in Bacillus subtilis. Journal of General Microbiology 129, 2091-2101.

ERrington, J. \& Mandelstam, J. (1984). Genetic and phenotypic characterization of a cluster of mutations in the spoVA locus of Bacillus subtilis. Journal of General Microbiology 130, 2115-2121.

Ferrari, F. A., Nguyen, A., Lang, D. \& Hoch, J. A. (1983). Construction and properties of an integrable plasmid for Bacillus subtilis. Journal of Bacteriology 154, 1513-1515.

FORT, P. \& Piggot, P. J. (1984). Nucleotide sequence of sporulation locus spollA in Bacillus subtilis. Journal of General Microbiology 130, 2147-2153.

Guo, L.-H., YANG, R. C. A. \& WU, R. (1983). An improved strategy for rapid direct sequencing of both strands of long DNA molecules cloned in a plasmid. Nucleic Acids Research 11, 5521-5540.

Haldenwang, W. G., Banner, C. D., Ollington, J. F., LoSICK, R., HOCH, J. A., O'CONNOR, M. B. \& Sonenshein, A. L. (1980). Mapping a cloned gene under sporulation control by insertion of a drug resistance marker into the Bacillus subtilis chromosome. Journal of Bacteriology 142, 90-98.

$\mathrm{HoCH}$, J. A. (1971). Selection of cells transformed to prototrophy for sporulation markers. Journal of Bacteriology 105, 1200-1201.

HopwOod, D. A. (1970). The isolation of mutants. Methods in Microbiology 3A, 363-433.

Horinouchi, S. \& WeIsBLUM, B. (1982). Nucleotide sequence and functional map of pC194, a plasmid that specifies inducible chloramphenicol resistance. Journal of Bacteriology 150, 815-825.

Iordanescu, S., Surdeanu, M., Della latta, P. \& NovicK, R. (1978). Incompatibility and molecular relationships between small staphylococcal plasmids carrying the same resistance marker. Plasmid 1, 168179.

Jenkinson, H. F. \& Mandelstam, J. (1983). Cloning of the Bacillus subtilis lys and spoIIIB genes in phage $\phi 105$. Journal of General Microbiology 129, 22292240.

Johnson, W. C. \& TIPPER, D. J. (1981). Acid-soluble spore proteins of Bacillus subtilis. Journal of Bacteriology 146, 972-982.

Karmazyn, C., Anagnostopoulos, C. \& Schaeffer, P. (1972). Codominance of spoOA mutations in $\mathrm{spo}^{+} / \mathrm{spo}^{-}$merodiploid strains of Bacillus subtilis. In Spores V, pp. 126-132. Edited by H. O. Halvorson, R. S. Hanson \& L. L. Campbell. Washington, DC: American Society for Microbiology.

Karmazyn, C., Anagnostopoulos, C. \& Schaeffer, P. (1973). Caractère récessif de certaines mutations affectant la sporulation. Annales de l'Institut Pasteur 124, 125-138.

Kawamura, F., Saito, H. \& Ikeda, Y. (1979). A novel method for construction of specialized transducing phage $\rho 11$ of Bacillus subtilis. Gene 5, 87-91.

Kawamura, F., Shimotsu, H., Saito, H., Hirochika, H. \& Kobayashi, Y. (1981). Cloning of spo0 genes with bacteriophage and plasmid vectors in Bacillus subtilis. In Sporulation and Germination, pp. 109113. Edited by H. S. Levison, A. L. Sonenshein \& D. J. Tipper. Washington, DC: American Society for Microbiology.
LAMONT, I. L. (1984). A detailed genetic analysis of closely-linked sporulation mutations in Bacillus subtilis. D. Phil. thesis, University of Oxford, UK.

LiU, H.-M., ChaK, K. F. \& Piggot, P. J. (1982). Isolation and characterization of a recombinant plasmid carrying a functional part of the Bacillus subtilis spoIIA locus. Journal of General Microbiology 128, 2805-2812.

MandelstaM, J. (1976). Bacterial sporulation: a problem in the biochemistry and genetics of a primitive developmental system. Proceedings of the Royal Society B193, 89-106.

MARTIN, R. B. (1964). Introduction to Biophysical Chemistry. New York \& San Francisco: McGrawHill.

Mclaughlin, J. R., Murray, C. L. \& Rabinowitz, J. C. (1981). Unique features in the ribosome binding site sequence of the Gram-positive Staphylococcus aureus $\beta$-lactamase gene. Journal of Biological Chemistry 256, 11283-11291.

Messing, J. (1983). New M13 vectors for cloning. Methods in Enzymology 101, 20-78.

Messing, J., Crea, R. \& Seeburg, P. H. (1981). A system for shotgun DNA sequencing. Nucleic Acids Research 9, 309-321.

Moran, C. P., JR, Lang, N., Le Grice, S. F. J., Lee, G., Stephens, M., Sonenshein, A. L., Pero, J. \& Losick, R. (1982). Nucleotide sequences that signal the initiation of transcription and translation in Bacillus subtilis. Molecular and General Genetics 186, 339-346.

Piggot, P. J. \& CoOte, J. G. (1976). Genetic aspects of bacterial endospore formation. Bacteriological Review's 40, 908-962.

Piggot, P. J., Molr, A. \& SMith, D. A. (1981). Advances in the genetics of Bacillus subtilis differentiation. In Sporulation and Germination, pp. 29-39. Edited by H. S. Levinson, A. L. Sonenshein \& D. J. Tipper. Washington, DC: American Society for Microbiology.

Piggot, P. J., Curtis, C. A. M. \& Lencastre, H. DE (1984). Demonstration of a polycistronic transcriptional unit required for sporulation of Bacillus subtilis by use of integrational plasmid vectors. Journal of General Microbiology 130, 2123-2136.

Poncz, M., Solowiejczyk, D., Ballantine, M., Schwartz, E. \& Surrey, S. (1982). "Nonrandom" DNA sequence analysis in bacteriophage M13 by the dideoxy chain-termination method. Proceedings of the National Academy' of Sciences of the United States of America 79, 4298-4302.

Ramakrishna, N., Dubnau, E. \& Smith, I. (1984). The complete DNA sequence and regulatory regions of the Bacillus licheniformis spoOH gene. Nucleic Acids Research 12, 1779-1790.

Sanger, F., Nicklen, S. \& Coulson, A. R. (1977) DNA sequencing with chain terminating inhibitors Proceedings of the National Academy of Sciences of the United States of America 74, 5463-5467.

Sanger, F., Coulson, A. R., Barrell, B. G., Smith, A. J. H. \& RoE, B. A. (1980). Cloning in singlestranded bacteriophage as an aid to rapid DNA sequencing. Journal of Molecular Biology 143, 161178.

Savva, D. \& Mandelstam, J. (1984). Cloning of the Bacillus subtilis spollA and spoVA genes in phage 
$\phi 105 \mathrm{DI}$ : 1t. Journal of General Microbiology 130 , $2137-2145$.

Schaeffer, P., Ionesco, H., Ryter, A. \& Balassa, G. (1965). La sporulation de Bacillus subtilis: étude génétique et physiologique. Colloques internationaux du Centre national de la recherche scientifique 124, $553-563$.

SEGALL, J. \& Losick, R. (1977). Cloned Bacillus subtilis DNA containing a gene that is activated early during sporulation. Cell 11, 751-761.

Shimotsu, H., Kawamura, F., Kobayashi, Y. \& SAITo, H. (1983). Early sporulation gene spoOF: nucleotide sequence and analysis of gene product. Proceedings of the National Academy of Sciences of the United States of America 80, 658-662.

Shine, J. \& Dalgarno, L. (1974). The 3' terminal sequence of Escherichia coli $16 \mathrm{~S}$ ribosomal RNA complementarity to nonsense triplets and ribosome binding sites. Proceedings of the National Academy of Sciences of the United States of America 71, 13421346.

Southern, E. M. (1975). Detection of specific sequences among DNA fragments separated by gel electrophoresis. Journal of Molecular Biology 98, 503-517.

STADEN, R. (1977). Sequence data handling by computer. Nucleic Acids Research 4, 4037-4051.
Staden, R. (1982). Automation of the computer handling of gel reading data produced by the shotgun method of DNA sequencing. Nucleic Acids Research 10, 4731-4751.

Staden, R. \& Mclachlan, A. D. (1982). Codon preference and its use in identifying protein coding regions in long DNA sequences. Nucleic Acids Research 10, 141-156.

Tinoco, I., JR, Borer, P. N., Dengler, B., Levine, M. D., Uhlenbeck, O. C., Crothers, D. M. \& Gralla, J. (1973). Improved estimation of secondary structure in ribonucleic acids. Nature New Biology 246, 40-41.

Trowsdale, J. \& Anagnostopoulos, C. (1975). Evidence for the translocation of a chromosome segment in Bacillus subtilis strains carrying the trpE26 mutation. Journal of Bacteriology 122, 886898.

YANG, M., Galizzi, A. \& Henner, D. (1983). Nucleotide sequence of the amylase gene from Bacillus subtilis. Nucleic Acids Research 11, 237-249. YounG, M. (1983). The mechanism of insertion of a segment of heterologous DNA into the chromosome of Bacillus subtilis. Journal of General Microbiology 129, 1497-1512. 